\title{
Removal of Hardening Salts by Nanofiltration Composite Membranes
}

\author{
${ }^{1}$ Dinar D. Fazullin, ${ }^{2}$ Gennady V. Mavrin, ${ }^{3}$ Inar A. Nasyrov, ${ }^{4}$ Leysan I. Fazullina \\ ${ }^{1-4}$ Kazan Federal University \\ Email:denr3@yandex.ru
}

Received: $2^{\text {th }}$ August 2019, Accepted: $30^{\text {th }}$ September 2019, Published: $31^{\text {st }}$ October 2019

\begin{abstract}
For removal of hardness salts, composite nanofiltration membranes with a "nylon-PS" polystyrene (PS) surface layer, a cellulose acetate (AC) surface layer on a nylon "nylon-AC" substrate, and a cellulose acetate surface layer on a polytetrafluoroethylene (PTFE) substrate were obtained "PTFE-AC". To increase the retention capacity, several layers of polymer particles were applied to the surface of the substrate. The content of the composite membrane layer ranged from 9.2 to $18.6 \%$ by weight, depending on the number of layers. To stabilize the surface layer, the membrane was finally to heat treatment. According to scanning electron microscopy data, it was established that spherical polystyrene particles with sizes up to $10 \mu \mathrm{m}$ are located on the surface and in the pores of the substrate. And the cellulose acetate particles of cellulose are located in the pores of the PTFE substrate. A decrease in the specific performance of the membranes with an increase in the number of surface layers has been established. The specific productivity of the dynamic membrane was $369 \mathrm{dm}^{3} / \mathrm{m}^{2} \cdot \mathrm{h}$, and for composite membranes with a surface layer of cellulose acetate higher than 2 times: $631-755 \mathrm{dm}^{3} / \mathrm{m}^{2} \cdot \mathrm{h}$ at an operating pressure of $0.2 \mathrm{MPa}$, which is 3 to 7 times higher than with industrial nanofiltration membrane. The "PTFE-AC" and "nylon-PS" membranes showed high retention capacity in terms of overall hardness: $76.3 \%$ and $73.7 \%$, respectively.
\end{abstract}

\section{Keywords}

Nylon, Polystyrene, Scanning Electron Microscopy, Composite Membrane, Cellulose Acetate, Polytetrafluoroethylene, Hardness Salts, Total Hardness.

\section{Introduction}

Water hardness is a combination of chemical and physical properties of water associated with the content of dissolved salts of alkaline earth metals in it, mainly calcium and magnesium. Ions of calcium $\left(\mathrm{Ca}^{2+}\right)$ and magnesium $\left(\mathrm{Mg}^{2+}\right)$, as well as other alkaline earth metals, are present in all mineralized waters. Their source is natural deposits of limestone, gypsum, and dolomites.

Hard water forms scale on the walls of heating boilers, batteries, which significantly impairs their thermal performance. Scale accounts for $90 \%$ of failures in water heating equipment. Therefore, water subjected to heating in boilers, boilers, etc. higher rigidity requirements are imposed. A thin layer of scale on the heating surface is not at all harmless, since the duration of heating through a scale layer with low thermal conductivity gradually increases, the bottom burns out faster and faster - after all, the metal cools more slowly and slowly each time, it remains in a heated state for a long time. In the end, it may happen that the bottom of the vessel does not survive and begins to leak. This fact is very dangerous in the industry where steam boilers are used.

Water used for domestic purposes must undergo not only thorough cleaning but also softening. Otherwise, there is a high risk of premature failure of expensive equipment or an increase in maintenance costs. To eliminate hardness salts, there are many methods and methods. For example, the thermal method - is associated with the heating of water, as a result of which carbonate hardness decreases; reagent methods - based on the treatment of water with reagents that form poorly soluble compounds with calcium and magnesium that precipitate or are removed by filtration; thermochemical method - carried out with the addition of lime and soda or caustic soda and soda at a water temperature of more than $100^{\circ} \mathrm{C}$. These methods of eliminating hardness salts are energy-intensive and lead to water pollution with the reagents used.

Methods for removing hardness salts based on freezing and distilling water are only suitable for softening a small amount of water. Baromembrane processes [1-3], such as reverse osmosis or nanofiltration, and ion exchange methods $[4,5]$ are highly effective and less energy-consuming methods for removing hardness salts. Of the baromembrane methods for removing hardness salts, nanofiltration is the most acceptable, since it has higher productivity and requires a lower working pressure for the separation process compared to reverse osmosis. The use of ion exchange resins for water softening is limited by their exchange capacity and the need to replace or regenerate using chemical reagents, followed by washing with deionized water.

In this regard, it is promising to create composite nanofiltration membranes with high specific productivity at low working pressure and high retention capacity of hardness salts.

This work aims to develop a method for removing stiffness salts by nanofiltration using composite membranes, as well as to determine the parameters of membrane separation and the retention of membranes. 


\section{Methods}

To remove hardness salts, dynamic multilayer membranes with a surface layer of nylon-PS polystyrene were obtained; composite membranes with a surface layer of acetate-cellulose on a substrate of nylon "nylon-AC" and composite membranes with a surface layer of acetate-cellulose on a substrate of polytetrafluoroethylene (PTFE) "PTFE-AC".

Dynamic nanofiltration membranes consist of four layers of polystyrene, with particle sizes less than $100 \mathrm{~nm}$. A microfiltration polymer membrane made of nylon with an average pore size of $0.45 \mu \mathrm{m}$ and a diameter of $47 \mathrm{~mm}$ was used as the initial substrate, on the surface of which a dynamic layer was applied. The stabilization of the surface layer was carried out by heat treatment.

To obtain composite membranes with a surface layer of cellulose acetate-nylon-AC and PTFE-AC as the initial substrate, on the surface of which a new layer of cellulose acetate was applied, a microfiltration polymer membrane made of PTFE and nylon (manufacturer - "Phenex Filter Membranes ", pore size $0.45 \mu \mathrm{m}$ ). To obtain the composite layer, a $5 \%$ solution of cellulose acetate in acetone was used. The surface layer was obtained by forming on the surface of the porous base a semipermeable layer of dissolved cellulose acetate present in the acetone aerosol. The stabilization of the surface layer was carried out by heat treatment.

The polystyrene content in the membrane was determined by the gravimetric method, by the weight of the membrane before and after modification.

The change in the surface structure of the membranes was recorded using a scanning electron microscope brand "LEO1430 VP" manufacturer Carl Zeiss. Samples were glued onto aluminum plates; the surface of the membranes was sprayed with gold, by cathodic deposition in argon, and viewed in high vacuum.

As the main indicators of the membrane separation process, we considered the specific productivity and the retention ability of the membranes in terms of water hardness, which was calculated as the ratio of the content of hardness salts in water before and after membrane separation. In the process of membrane separation, the working pressure of $0.2 \mathrm{MPa}$ was applied, the temperature of the liquid was $25^{\circ} \mathrm{C}$.

The method for determining the total hardness is based on titration of the sample with a solution of disodium salt of ethylenediaminetetraacetic acid (Trilon B) in the presence of an indicator of black Eriochrom $\mathrm{T}$, resulting in complex compounds of Trilon $\mathrm{B}$ with calcium and magnesium ions being formed at a $\mathrm{pH}$ of about 10 .

For the membrane separation process, tap water was used with a total hardness value of $3.8 \mathrm{mmol} / \mathrm{dm}^{3}$.

To compare the results of the retarding ability of a dynamic membrane, hardness salts from tap water were removed using an industrial nanofiltration membrane brand "EMO-N-350".

\section{Results and Discussion}

The results of the study of the membrane surface by scanning electron microscopy with a magnification of 2000 times are presented in Figure 1. 



Figure 1: Micrographs of the Membranes: a) The Original Membrane of Nylon; b) Dynamic Membrane with a Surface Layer of Polystyrene "Nylon-PS"; c) Polytetrafluoroethylene Base Membrane; d) Composite Membrane with a Surface Layer of Cellulose Acetate "PTFE-AC" (An Increase of 1000 times).

According to Figure 1b), it is seen that after modifying the nylon substrate with a polystyrene suspension, spherical polystyrene particles up to $10 \mu \mathrm{m}$ in size were formed on the surface and in the pores. It is also seen that after modification the number of open areas decreased.

Figure $1 \mathrm{c}$ ) shows the initial PTFE membrane on the surface, which was applied to the cellulose acetate particles present in the acetone aerosol. Figure $1 \mathrm{~d}$ ) shows that the particles of cellulose acetate are not located on the surface of the substrate from PTFE, but in the depths of its structure in the pores.

After modifying the membranes, we studied the parameters of the membrane separation process, one of the main of which is the specific productivity of the membranes. The results of studies on the specific productivity of the membranes are presented in the table. 1 .

\begin{tabular}{|l|l|c|c|}
\hline \multicolumn{1}{|c|}{ Membrane } & $\begin{array}{c}\text { The surface layer and its share of } \\
\text { the total mass of the } \\
\text { membrane, } \%\end{array}$ & $\begin{array}{c}\text { Number of } \\
\text { layers }\end{array}$ & $\begin{array}{c}\text { The specific capacity of } \\
\text { membranes, } \mathrm{dm}^{3} / \mathrm{m}^{2} \cdot \mathrm{h}\end{array}$ \\
\hline \multirow{2}{*}{$\begin{array}{l}\text { dynamic membrane "Nylon- } \\
\text { PS" }\end{array}$} & Polystyrene, $11.5 \%$ & 2 & 1215 \\
\cline { 2 - 4 } & Polystyrene, $15.6 \%$ & 3 & 822 \\
\cline { 2 - 4 } $\begin{array}{l}\text { composit membrane "PTFE- } \\
\text { AC" }\end{array}$ & Celystyrene, $18.6 \%$ & 4 & 369 \\
\cline { 2 - 4 } & Cellulose Acetate, $9.2 \%$ & 2 & 3119 \\
\hline
\end{tabular}




\begin{tabular}{|c|c|c|c|}
\hline & Cellulose Acetate, $16.5 \%$ & 4 & 755 \\
\hline \multirow{3}{*}{$\begin{array}{l}\text { composite membrane "Nylon- } \\
\text { AC" }\end{array}$} & Cellulose Acetate, $9.8 \%$ & 2 & 2631 \\
\hline & Cellulose Acetate, $14.9 \%$ & 3 & 1101 \\
\hline & Cellulose Acetate, $18.1 \%$ & 4 & 631 \\
\hline $\begin{array}{l}\text { Polyamide nanofiltration } \\
\text { membrane "OPMN - P" }\end{array}$ & Polyamide & - & 100 (at $1.6 \mathrm{MPa}$ ) [6] \\
\hline
\end{tabular}

Table 1: Specific Productivity of Distilled Tap Water, With a Working Pressure of 0.2 MPa

According to table 1, the specific productivity of dynamic nylon-PS membranes is lower than that of composite membranes with a surface layer of cellulose acetate, which is associated with the hydrophobicity of the surface layer of polystyrene and in a denser arrangement of polystyrene particles in the surface and in the pores of the substrate due to high pressure attached surface in the process of forming a dynamic layer. It was also found that the specific productivity of the membranes decreases as the number of surface layers increases. The specific productivity of the obtained membranes was compared with the data of the industrial polyamide nanofiltration membrane of the brand "OPMN - P" manufactured by the Scientific and Technical Center "Vladipor". The productivity of this membrane is 4-7 times lower at a working pressure of $1.6 \mathrm{MPa}$ compared with the performance of the obtained composite membranes.

The determination of the retention ability of the membranes was evaluated by the total water hardness. $300 \mathrm{~cm}^{3}$ of tap water with a total hardness of $3.8 \mathrm{mmol} / \mathrm{dm}^{3}$ were passed through the membranes. The filtrate volume was $270 \mathrm{~cm}^{3}$. The results for the total hardness of the filtrate of tap water are presented in table 2.

\begin{tabular}{|c|c|c|c|c|c|}
\hline \multirow{2}{*}{ Membrane } & \multirow{2}{*}{$\begin{array}{l}\text { The surface layer and its share of } \\
\text { the total mass of the membrane, } \%\end{array}$} & \multirow{2}{*}{$\begin{array}{l}\text { Number of } \\
\text { layers }\end{array}$} & \multicolumn{2}{|c|}{$\begin{array}{l}\text { Total hardness mmol / } \\
\mathrm{dm}^{3}\end{array}$} & \multirow{2}{*}{$\begin{array}{l}\text { Retention } \\
\text { capacity, } \%\end{array}$} \\
\hline & & & source & filtrate & \\
\hline \multirow{3}{*}{$\begin{array}{l}\text { dynamic } \\
\text { membrane } \\
\text { "Nylon-PS" }\end{array}$} & Polystyrene, $11.5 \%$ & 2 & \multirow{10}{*}{3.8} & 2.3 & 39.5 \\
\hline & Polystyrene, $15.6 \%$ & 3 & & 1.8 & 57.1 \\
\hline & Polystyrene, $18.6 \%$ & 4 & & 1,0 & 73.7 \\
\hline \multirow{3}{*}{$\begin{array}{l}\text { composite } \\
\text { membrane } \\
\text { "PTFE-AC" }\end{array}$} & Cellulose Acetate, $9.2 \%$ & 2 & & 2.7 & 28.9 \\
\hline & Cellulose Acetate, $12.4 \%$ & 3 & & 1.8 & 57.1 \\
\hline & Cellulose Acetate, $16.5 \%$ & 4 & & 0.9 & 76.3 \\
\hline \multirow{3}{*}{$\begin{array}{l}\text { composite } \\
\text { membrane } \\
\text { "Nylon-AC" }\end{array}$} & Cellulose Acetate, $9.8 \%$ & 2 & & 2.6 & 31.6 \\
\hline & Cellulose Acetate, $14.9 \%$ & 3 & & 2.3 & 39.5 \\
\hline & Cellulose Acetate, $18.1 \%$ & 4 & & 1.8 & 57.1 \\
\hline $\begin{array}{l}\text { nanofiltration } \\
\text { membrane } \\
\text { "EMO-H-350" }\end{array}$ & Polysulfonamide & - & & 0.5 & 86.8 \\
\hline $\begin{array}{l}\text { Polyamide } \\
\text { nanofiltration } \\
\text { membrane } \\
\text { "OPMN - P" }\end{array}$ & Polyamide & - & - & - & $98.0\left(\mathrm{MgSO}_{4}\right)$ \\
\hline
\end{tabular}

Table 2: Membrane Retention Capacity in terms of Total Hardness

According to Table 2, the initial concentration of hardness salts is $3.8 \mathrm{mmol} / \mathrm{dm}^{3}$. After water separation through composite membranes, the concentration of hardness salts is from 2.6 to $0.9 \mathrm{mmol} / \mathrm{dm}^{3}$ depending on the number of layers. With an increase in the number of composite layers, the retention capacity of the membranes increases. The "PTFE-AC" membranes - 76.3\% and "Nylon-PS" - 73.7\% have a high retention ability, the maximum retention ability of the "Nylon-AC" membrane was $57.1 \%$. The holding capacity of a roll of nanofiltration membrane brand "EMO-N350 " made of polysulfonamide was $86.8 \%$, at a working pressure of $0.6 \mathrm{MPa}$.

In an industrial nanofiltration membrane made of polyamide, the $\mathrm{MgSO}_{4}$ solution retention capacity according to published data is $98 \%$, with productivity 3 times lower than composite membranes. Also, for this membrane, high working pressure is required - 1.6 MPa, which is 8 times higher than the pressure that is necessary for the separation of solutions with the composite membrane.

\section{Summary}

To remove hardness salts, composite nanofiltration membranes with a surface layer of nylon-PS polystyrene were obtained; composite membranes with a surface layer of acetate-cellulose on a substrate of nylon "nylon-AC" and composite membranes with a surface layer of acetate-cellulose on a substrate of polytetrafluoroethylene (PTFE) "PTFEAC". Dynamic nylon-PS membranes were obtained by forming on the nylon substrate a semipermeable layer of polystyrene particles present in the suspension during filtration through the membrane. Composite membranes were prepared on a substrate of nylon and PTFE from an aerosol containing cellulose acetate particles. 
To increase the retention ability, several layers of polymer particles were applied to the surface of the substrate. The content of the composite membrane layer ranged from 9.2 to $18.6 \%$ by weight depending on the number of layers. To stabilize the surface layer, the membrane was subjected to heat treatment.

According to scanning electron microscopy, it was found that spherical polystyrene particles up to $10 \mu \mathrm{m}$ in size are located on the surface and in the pores of the substrate. And cellulose acetate particles of cellulose are arranged in the pores of a PTFE substrate.

It was also found that the specific productivity of the membranes decreases as the number of surface layers increases. The specific productivity of the dynamic membrane was $369 \mathrm{dm}^{3} / \mathrm{m}^{2} \cdot \mathrm{h}$, and for composite membranes with a surface layer of cellulose acetate 2 times higher: $631-755 \mathrm{dm}^{3} / \mathrm{m}^{2} \cdot \mathrm{h}$ at operating pressure $0.2 \mathrm{MPa}$, which is $3-7$ times higher compared to the industrial nanofiltration membrane.

The "PTFE-AC" and "Nylon-PS" membranes showed high retention ability in terms of total hardness: $76.3 \%$ and $73.7 \%$, respectively.

\section{Conclusions}

Water with a high value of total hardness is not very suitable for technological needs and requires the removal of hardness salts. Of the membrane processes for the removal of hardness salts, the most effective is the process of nanofiltration. The retention capacity of the obtained composite membranes in terms of total hardness was 73-76\%, with specific productivity of $370-755 \mathrm{dm}^{3} / \mathrm{m}^{2} \cdot \mathrm{h}$, which allows the use of these membranes for preliminary water treatment before the reverse osmosis process to obtain demineralized water.

\section{Acknowledgments}

The work is performed according to the Russian Government Program of Competitive Growth of Kazan Federal University. The work was supported by a grant from the President of the Russian Federation for state support of young Russian scientists - PhDs (MK-1107.2019.8) and with financial support from Kazan (Volga Region) Federal University.

\section{References}

[1] D.D. Fazullin. Utilization of waste lubricating-cooling fluids by membrane methods / D.D. Fazullin, G.V. Mavrin, M.P. Sokolov / Chemistry and Technology of Fuels and Oils. 2015. Vol. 1. pp. 93-98.

[2] Sahinkaya Erkan. Concentrate minimization and water recovery enhancement using pellet precipitator in a reverse osmosis process treating textile wastewater / Erkan Sahinkaya, Ahmet Sahin, Adem Yurtsever / Journal of Environmental Management. 2018. Vol. 222. pp. 420-427.

[3] Ates Nuray. Removal of heavy metals from aluminum anodic oxidation wastewaters by membrane filtration / Nuray Ates, Nigmet Uzal / Environmental Science And Pollution Research. 2018. Vol. 25. Issue 22SI. pp. 2225922272.

[4] Alharati Assma. Boron removal from seawater using a hybrid sorption/microfiltration process without continuous addition of resin / Assma Alharati, Jean-Pierre Valor, Sebastien Urbaniak / Chemical Engineering, and Processing. 2018. Vol. 131. pp. 227-233

[5] N.P.G.N. Chandrasekara. Regeneration of strong acid / strong base mixed-bed resins using ammonium bicarbonate (AB) for a sustainable desalination process / NPGN Chandrasekara, RM Pashley / Desalination. 2017. Vol. 409. pp. $1-6$.

[6] ZAO Scientific and Technical Center "Vladipor". Nanofiltration membranes. http://www.vladipor.ru/catalog/\&cid=004 